Article

\title{
Assessment of a New Silicon Carbide Tubular Honeycomb Membrane for Treatment of Olive Mill Wastewaters
}

\author{
Maria C. Fraga ${ }^{1,2}$, Sandra Sanches ${ }^{2}$, João G. Crespo ${ }^{1, *}$ and Vanessa J. Pereira ${ }^{2, *}$ \\ 1 REQUIMTE/LAQV, Department of Chemistry, Faculdade de Ciências e Tecnologia, \\ Universidade Nova de Lisboa, Campus de Caparica, 2829-516 Caparica, Portugal; carmo.fraga@itqb.unl.pt \\ 2 Instituto de Biologia Experimental e Tecnológica, Apartado 12, 2781-901 Oeiras, Portugal; \\ sandras@itqb.unl.pt \\ * Correspondence: jgc@fct.unl.pt (J.G.C.); vanessap@itqb.unl.pt (V.J.P.); \\ Tel.: +351-212-948-550 (J.G.C.); +351-214-469-554 (V.J.P.)
}

Academic Editor: Dionysios Demetriou Dionysiou

Received: 18 January 2017; Accepted: 22 February 2017; Published: 27 February 2017

\begin{abstract}
Extremely high removals of total suspended solids and oil and grease were obtained when olive mill wastewaters were filtered using new silicon carbide tubular membranes. These new membranes were used at constant permeate flux to treat real olive mill wastewaters at pilot scale. The filtration conditions were evaluated and optimized in terms of the selection of the permeate flux and flux maintenance strategies employed-backpulsing and backwashing-in order to reduce fouling formation. The results obtained reveal that the combination of backpulses and backwashes helps to maintain the permeate flux, avoids transmembrane pressure increase and decreases the cake resistance. Moreover, membrane cleaning procedures were compared and the main agents responsible for fouling formation identified. Results also show that, under total recirculation, despite an increased concentration of pollutants in the feed stream, the quality of the permeate is maintained. Membrane filtration using silicon carbide membranes is an effective alternative to dissolved air flotation and can be applied efficiently to remove total suspended solids and oil and grease from olive mill wastewaters.
\end{abstract}

Keywords: Silicon carbide; membrane filtration; pilot scale; olive mill wastewaters; flux maintenance strategies; fouling prevention

\section{Introduction}

Oily wastewaters are one of the main pollutants of the aquatic environment that, due to its hazardous nature, can cause serious environmental problems [1]. A large volume of these wastewaters is generated from various industrial processes, such as olive oil production, and needs to be treated before being discharged in the aquatic environment. The annual world production of olive oil, estimated in $2.5 \times 10^{6}$ tons, is one of the most important agricultural activities in the Mediterranean countries, which are responsible for the production of $97 \%$ of the total world's olive oil [2,3]. However, such a high production of olive oil also results in an extremely high production of wastewaters characterized by a high concentration of total suspended solids and organic compounds (polysaccharides, phenols, polyalcohols, proteins, organic acids and oil) [4-6]. The physical and chemical composition of olive mill wastewaters depend on several factors such as olive extraction processes and olive maturation as well as climatic and agronomic conditions $[7,8]$.

Due to the presence of phytotoxic and antibacterial phenolic substances, these wastewaters are often resistant to biological degradation [8,9]. Traditional treatment methods, including skimming, 
coagulation, flocculation, sedimentation and flotation, present disadvantages such as low efficiency in the treatment of stable emulsions, high sludge production, high operation costs or need to add chemicals. In this context, membrane technology has become a significant separation process over the last years [10-14], being efficient in treating stable emulsions, allowing high quality of permeate produced (the variation in feed water quality will have a minimal impact on permeate quality) and generating a small volume of waste requiring further treatment $[1,15]$. Moreover, membranes require small implementation areas and the use of chemicals is avoided. Regarding the costs, membrane processes present low investment and maintenance costs, high efficiency and low energy consumption [16]. The use of membrane technology can therefore be compared to conventional processes for different wastewater applications.

Membrane fouling and its consequent flux decline (when the filtration process is performed under constant transmembrane pressure) or transmembrane pressure increase (when the filtration process is performed under constant permeate flux conditions) is the main drawback of pressure-driven membrane separation processes. Even though most studies in the literature operate at constant transmembrane pressure, most industrial water purification membrane installations operate at constant flux [17]. Working at constant permeate flux seems to be a valid strategy to reduce the fouling occurrence rather than working at constant-pressure operation [18]. Miller et al. [19] compared membrane fouling in the filtration of oily wastewater with polysulfone membranes with $20 \mathrm{kDa}$ molecular weight cut off. They observed that, working below a specific threshold flux, a constant flux operation minimizes fouling appearance and membrane resistance.

It is important to define the permeate flux at which fouling is first observed for a given feed concentration to optimize the membrane process and minimize fouling $[20,21]$.

Besides defining an optimum operating permeate flux, different cleaning systems can be applied as flux maintenance strategies such as backpulse (BP), backwash (BW), chemically enhanced backwash (CEB) and cleaning in place (CIP) [21]. The effect of backpulses and backwashes in the microfiltration of oil-in-water emulsions with ceramic membranes was already studied and reported. Results show that these strategies are efficient in fouling prevention without decreasing the oil rejection [22-24]. From an economic point of view, a study comparing the microfiltration of emulsified crude oil with and without backpulses revealed that the process without backpulses is not economically viable when compared to conventional treatment methods. However, the same operation with regular backpulses resulted in lower costs of treated water when compared with conventional methods [25].

The use of ceramic membranes recently increased, mainly for application in industrial processes [26]. Due to their advantadges compared with polymeric membranes-including better thermal stability, mechanical resistance and chemical resistance-ceramic membranes can be applied in extremely aggressive environmental conditions [27]. These properties allow for better control of membrane fouling since higher pressures can be employed in backwashes and cleanings can be performed with stronger chemicals, while extending the membrane lifetime [28]. Satisfactory results in the treatment of oily wastewaters were reported when microfiltration ceramic membranes were used [22,23,29]. $\gamma$-alumina is often used as a support material for ultrafiltration membranes due to its smooth surface, in contrast to other materials, and since it is fairly inert. On the other hand, it can be easily deposited in macroporous supports. Nevertheless, $\gamma$-alumina do not present high enough chemical or mechanical stability when subject to severe conditions. A promising material for ceramic membranes is silicon carbide ( $\mathrm{SiC}$ ) since it presents better resistance to chemicals, and thus presents advantages when strong and repeated cleanings are required [30,31]. Moreover, when compared with polymeric and other ceramic membranes such as titania or zirconia, silicon carbide membranes present higher hydrophilicity and lower fouling tendency [32] and thus allow higher permeate fluxes in wastewater treatment.

In the present work, a new silicon carbide tubular ceramic membrane [33], with a single retentive layer on top of the substrate was tested, for the first time, to treat real olive mill wastewaters at pilot scale. This work focused in the optimization of constant flux filtration conditions. Backpulses 
and backwashes were studied in order to reduce the fouling formation and consequently avoid transmembrane pressure increase. The filtration studies were performed under total recirculation conditions and a final concentration test was conducted under optimized conditions. Different cleaning protocols were also tested in order to optimize the chemical cleaning of the membrane.

\section{Material and methods}

\subsection{Characterization of Pilot Scale Unit, Membranes and Wastewater Matrices}

Olive mill wastewater, collected after the sedimentation process at a real wastewater treatment plant, was processed in a pilot scale membrane filtration unit (LabBrain unit, depicted in Figure 1), with cleaning devices (backpulse and backwash) incorporated and automatic data acquisition of transmembrane pressure (TMP) and permeate flux.

The characteristics of the new tubular honeycomb silicon carbide membranes (produced by LiqTech, Ballerup, Denmark) used in this study are detailed in Table 1. These membranes were developed in the scope of a joint project, previously characterized in terms of morphology, chemical surface composition and effectiveness to treat a different matrix (sunflower oil wastewater) [33]. The manufacturing process of these new membranes allows time and economic savings when compared with commercially available membranes with two layers (a top and an intermediate layer). It is extremely interesting to observe that, in spite of the relatively low membrane porosity (Table 1), this membrane presents a high hydraulic permeability, possibly as a result of its high hydrophilic character. In this study, contact angle measurements were performed (KSV Instruments LTD, CAM 100, Helsinki, Finland, with the software KSV CAM2008) to further characterize the new membrane (Table 1). However, a stable contact angle could not be determined because the coating of the membrane is extremely hydrophilic and the water drop was readily absorbed by the membrane. For nine different zones of the membrane, the average first contact angle value was determined. In addition, since the water drop was readily absorbed by the membrane, the contact angle decrease was also followed over time in the nine different zones. The measurements were performed with frame intervals of $100 \mathrm{~ms}$. The contact angle values measured over time adjusted to a linear regression and the average of all the slopes obtained (velocity of decreasing contact angle) are also presented in Table 1.

The pilot scale installation is built in stainless steel (AISI-304) and all components in contact with liquids are stainless steel AISI-316 with Teflon-coated components or Viton/EPDM/Nitrile sealing gaskets. The LabBrain Unit (LiqTech, Ballerup, Denmark) is equipped with a feed pump (Grundfos CRN 1-3, Bjerringbro, Denmark) and a recirculation pump which generates the crossflow (Grundfos CRN 3-4, Bjerringbro, Denmark). The unit can be operated both under crossflow and semi-dead-end mode; in this work the filtration was performed in crossflow mode. The pressure and flow rate inside the system are controlled by adjusting the position of the regulating valves and the pump speed. All data from pressure transmitters, flow transmitters, temperature transmitters, pump settings and valve positions are stored in the internal memory of the unit.

In addition, the unit is equipped with a Back Pulse Hammer (BPH). The BPH system is a pulse generator delivering high frequency "block" pulses from the permeate side, back through the membrane in order to keep the membrane clean and free of foulants. Backwash controlled by compressed air is also integrated in the unit. Both backpulses and backwashes can be performed manually or automatically. Various terminologies are applied in the literature regarding cleaning devices. In this work, the term "backpulse" will refer to very short air pulses generated from the permeate side, whose function is to loosen foulants, which are then removed by the crossflow. The term "backwash" will refer to the reversion of the permeate flow by means of a pump. In this case, the foulants on the membrane surface are washed away by the reversed permeate flow and removed by the crossflow. 


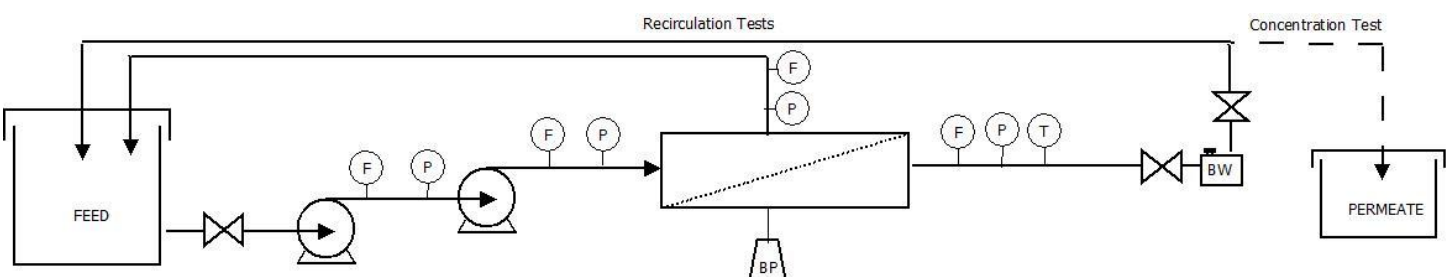

Figure 1. Scheme of the pilot filtration unit with cleaning devices (BP-Backpulse and BW-Backwash) used to treat the real olive mill wastewater in different operation modes (recirculation and concentration tests).

Table 1. Characteristics of the silicon carbide (SiC) membrane module used.

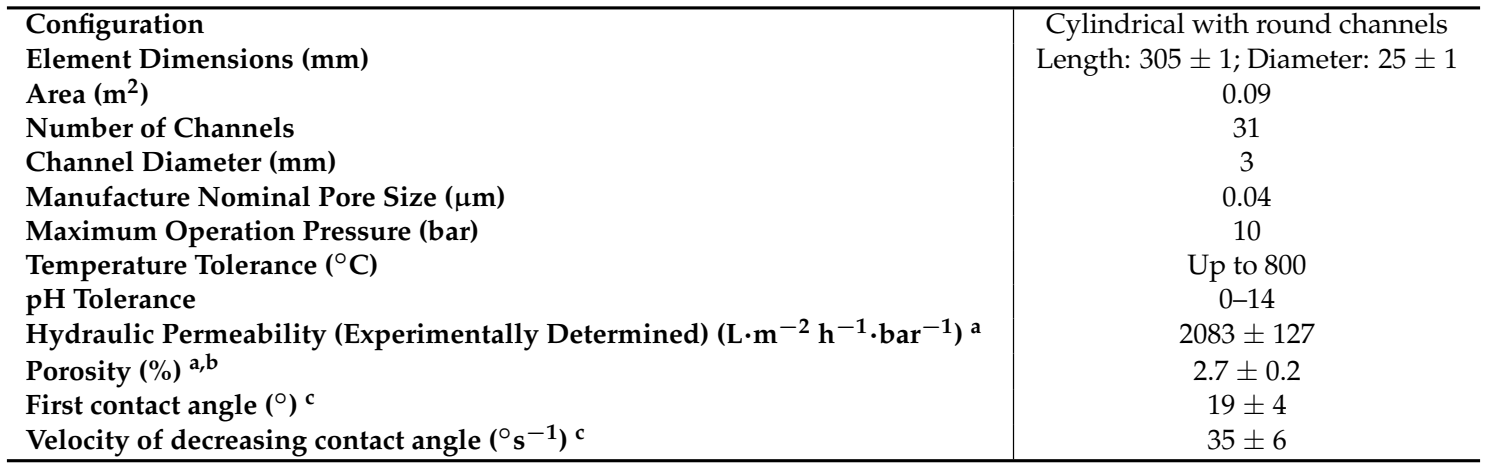

a: reference [33]; b: average of the values determined in two zones of the membrane; c: average of the values determined in nine zones of the membrane.

Table 2 presents an average of the parameters analysed (total solids-Standard Method 2540B [34], total suspended solids—Standard Method 2540D [34], chemical oxygen demand (COD)—Standard Method 5220 [34], total organic carbon (TOC) -Standard Method 5310B and oil and grease-Standard Method 5520C [34]) of the wastewater samples collected in six different sampling events corresponding to the six tests performed, showing that concentration of the five parameters analysed are highly superior to the limits imposed by the legislation for direct discharge in watercourses.

Table 2. Characterization of the real olive mill wastewater samples collected and limits imposed by legislation.

\begin{tabular}{cccc}
\hline Parameter & Average Concentration & $\begin{array}{c}\text { Portuguese Legislation } \\
\text { (DL 236/98) } \\
\text { Concentration }\end{array}$ & $\begin{array}{c}\text { European Legislation } \\
\text { (91/271/EEC) } \\
\text { Concentration }\end{array}$ \\
\hline Total solids $(\mathrm{mg} / \mathrm{L})$ & $6260 \pm 770$ & n.d. & n.d. \\
Total suspended solids & $2010 \pm 1105$ & 60 & 35 \\
$(\mathrm{mg} / \mathrm{L})$ & $8720 \pm 1148$ & 150 & 125 \\
COD $(\mathrm{mg} \mathrm{O} / \mathrm{L})$ & $2555 \pm 301$ & n.d & n.d. \\
TOC $(\mathrm{mg} / \mathrm{L})$ & $275 \pm 60$ & 15 & n.d. \\
Oil and grease $(\mathrm{mg} / \mathrm{L})$ & & & \\
\hline
\end{tabular}

n.d.: not defined.

\subsection{Membrane Filtration Tests}

\subsubsection{Determination of Optimal Permeate Flux Conditions}

To define the best operating flux that minimizes fouling for further application in long-term filtration assays, a preliminary study was carried out using the pretreated wastewater samples by 
assessing transmembrane pressure (TMP) variations under different constant permeate flowrates set during five-minute intervals. The selected permeate flux to conduct the experiments was the one at which a lower TMP variation was observed.

\subsubsection{Total Recirculation Tests}

Table 3 summarizes the operating conditions set in each filtration test. Four 24 h assays (tests 1-4) were conducted in total recirculation mode with a crossflow velocity set at $2 \mathrm{~m} \cdot \mathrm{s}^{-1}$ and the previously determined optimum permeate flux value.

Table 3. Permeate flux and flux maintenance strategies applied in the different filtration tests.

\begin{tabular}{|c|c|c|c|c|}
\hline Conditions & Test 1 & Test 2 & Test 3 & Test 4 \\
\hline Imposed constant permeate & 67 & 67 & 67 & 67 \\
\hline
\end{tabular}

During the $24 \mathrm{~h}$ long assays, the variation of transmembrane pressure was followed and the effect of backpulse (every $10 \mathrm{~min}$ ) and backwash (every 2 and $1 \mathrm{~h}$ ), employed as flux maintenance strategies, were studied. The permeate flux and pressure data acquisition in the LabBrain unit was automatically stored. A first test without cleaning strategies was performed (test 1). In order to study the effect of backpulses, a second test was carried out employing backpulses every 10 min (test 2). In tests 3 and 4 , besides backpulses every $10 \mathrm{~min}$, backwashes were also employed every two hours (test 3) and every hour (test 4) to study the effect of the combined flux maintenance strategies. These intervals were set based on experience of the manufacturer with other emulsified wastewaters and several assays performed with the unit and different wastewater qualities (data not shown).

The effectiveness of the membrane filtration assays was evaluated by monitoring TMP variation over time at the different imposed permeate fluxes and calculating the consequent membrane resistance levels as well as by determining the percent rejection and adsorption/deposition to the silicon carbide membranes of different water quality parameters (total solids, total suspended solids, chemical oxygen demand, total organic carbon and oil and grease). Samples were stored at $4{ }^{\circ} \mathrm{C}$ until analysis.

\subsubsection{Optimization of Membrane Cleaning}

In order to find out the best cleaning strategy to recover the permeability of the membrane, the effect of using different cleaning solutions and temperatures $\left(25^{\circ} \mathrm{C}\right.$ and $\left.65 \pm 5{ }^{\circ} \mathrm{C}\right)$ was studied. Solutions of $\mathrm{NaOH} 4 \%(\mathrm{w} / \mathrm{v})$ and citric acid $2 \%(\mathrm{w} / \mathrm{v})$ were tested. The recovery of the permeability achieved in each cleaning step was determined to understand the efficiency of each cleaning. The permeability of the membrane was considered to be restored when $90 \%$ of its hydraulic permeability was recovered. A mass balance was performed to compare the concentrations of different water quality parameters detected in the cleaning solutions with the levels of adsorption calculated in the filtration assays, to gain further knowledge about the efficiency of the different cleaning steps.

\subsubsection{Concentration Test}

In order to test conditions that best simulate the real conditions, a final concentration test was performed in the same unit. A quantity of $58 \mathrm{~L}$ of a pretreated olive mill wastewater was filtered with total recirculation of the retentate and total recovery of the permeate. Several samples were taken during the assay in order to evaluate the effectiveness of the membrane filtration in terms of the target parameters.

The starting conditions of the concentration test were set according to the optimum conditions selected in the total recirculation tests. Nevertheless, and due to a better quality of the wastewater received, no significant variation of TMP was observed after one hour of filtration; therefore, 
the permeate flux was incremented to $100 \mathrm{~L} \cdot \mathrm{m}^{-2} \cdot \mathrm{h}^{-1}$ to increase the water production. During the entire filtration assay, backpulses (every $10 \mathrm{~min}$ ) and backwashes (every hour) were applied. After the $7 \mathrm{~h}$ assay, a volume reduction factor of 5.2 was achieved.

\section{Results and Discussion}

\subsection{Membrane Filtration Tests}

\subsubsection{Determination of Controlled Permeate Flux Operating Conditions}

In order to determine the optimum permeate flux for the $24 \mathrm{~h}$ filtration assays, different controlled permeate fluxes were set for $5 \mathrm{~min}$ and the corresponding TMP values recorded. The chosen flux was the one for which a lower increase in TMP was observed, in order to ensure a minimal fouling under long-term operation.

Figure 2 shows the TMP increasing with the permeate flux variation. Due to limitations of the system used, it was not possible to test fluxes lower than $67 \mathrm{~L} \cdot \mathrm{m}^{-2} \cdot \mathrm{h}^{-1}$. Although some fouling was observed in each step, resulting in TMP increase in all of them, the value of $67 \mathrm{~L} \cdot \mathrm{m}^{-2} \cdot \mathrm{h}^{-1}$ was the chosen permeate flux to initiate the tests since at this permeate flux the lowest TMP increase was observed.

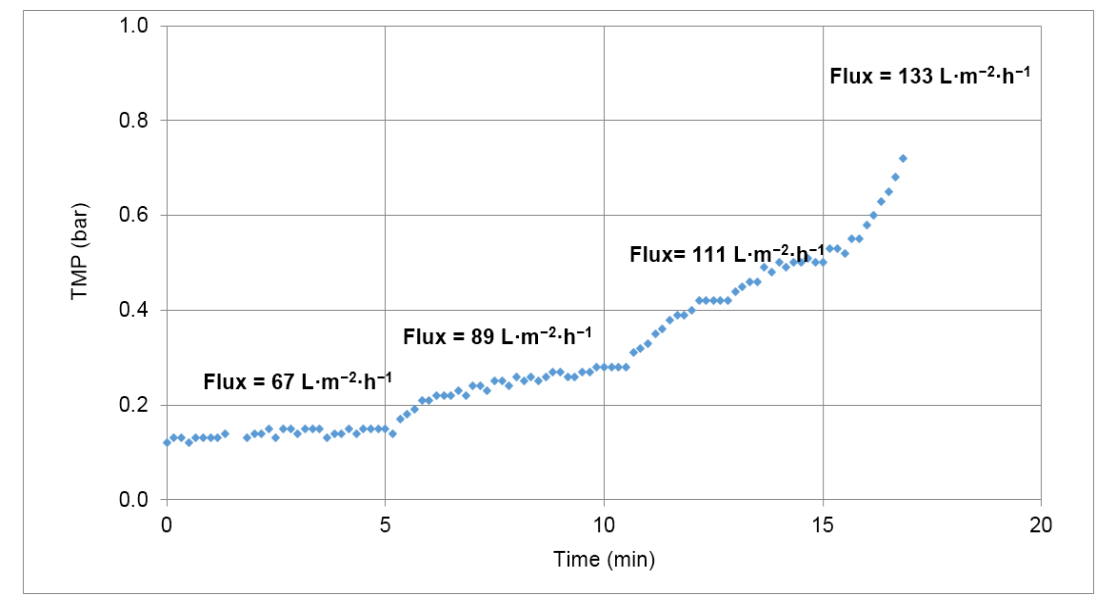

Figure 2. Variation of transmembrane pressure (TMP) with increase of controlled permeate flux.

\subsubsection{Total Recirculation Tests}

Figure 3 shows the TMP variation in the different $24 \mathrm{~h}$ assays conducted with the chosen permeate flux $\left(67 \mathrm{~L} \cdot \mathrm{m}^{-2} \cdot \mathrm{h}^{-1}\right)$ and different flux maintenance strategies (detailed in Table 3).

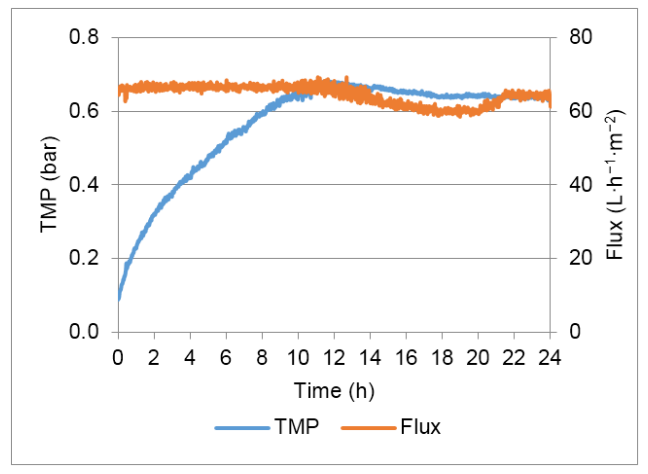

(a)

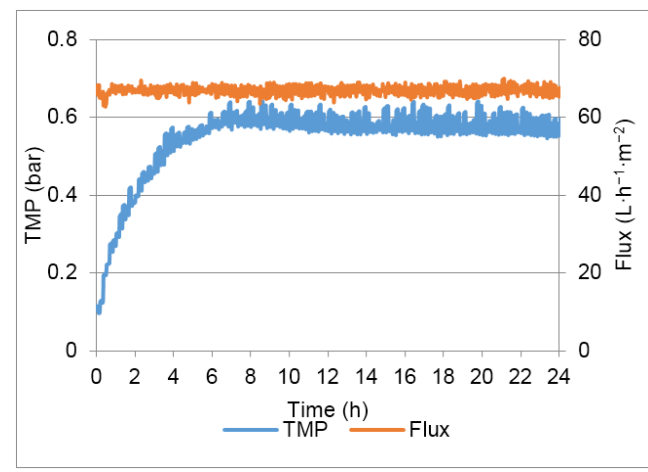

(b)

Figure 3. Cont. 


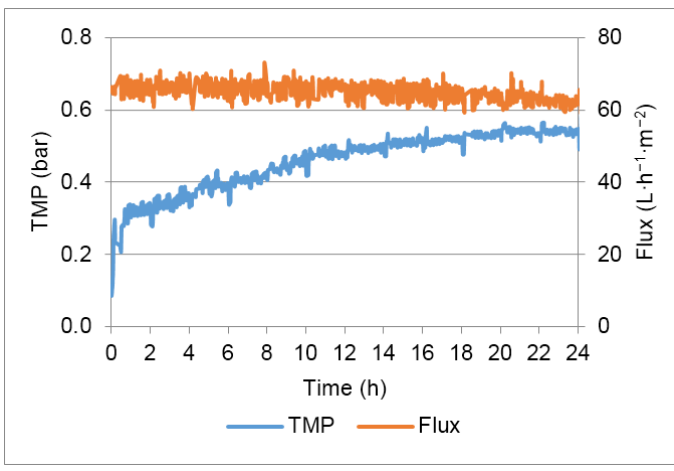

(c)

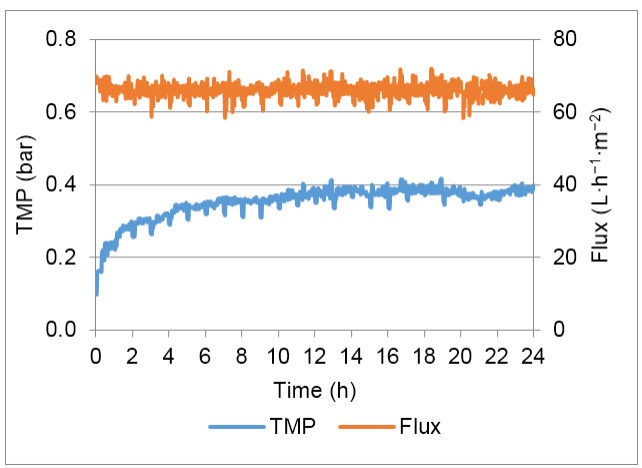

(d)

Figure 3. TMP and flux profiles obtained in the different assays: (a) test 1; (b) test 2; (c) test 3; (d) test 4.

The effectiveness of the different flux maintenance strategies was calculated using Equation (1), where $\triangle T M P_{T 1}$ is the total variation of the TMP in the $24 \mathrm{~h}$ of test without flux maintenance strategy (test 1 ) and $\triangle T M P_{\text {test }}$ refers to the variation of TMP in each test.

$$
\boldsymbol{\eta}(\%)=100 \times \frac{\left(\Delta T M P_{T 1}-\Delta T M P_{\text {test }}\right)}{\Delta T M P_{T 1}}
$$

In tests 2 and 3 a positive effect of backpulse (test 2) and backpulse combined with backwashing each $2 \mathrm{~h}$ (test 3 ) was observed compared with test 1 (no flux maintenance strategies and a TMP variation of 0.53 bar in the $24 \mathrm{~h}$ of assay). A transmembrane pressure variation of 0.48 and 0.43 bar in the $24 \mathrm{~h}$ was observed in tests 2 and 3, respectively. When the filtration assay was performed with backpulses each 10 min and backwashing each hour (test 4), a transmembrane pressure variation of 0.28 bar was obtained, nearly half the variation of transmembrane pressure observed when no flux maintenance strategies were applied, indicating that these strategies are rather efficient for fouling mitigation.

The higher effectiveness $(\mathfrak{\eta})$ value presented in Table 4 indicates a lower fouling potential when the combined flux maintenance strategies were applied in test 4 . The trend observed was expected: as the flux maintenance strategies are intensified, the effectiveness increases.

Table 4. Comparison of $\triangle T M P$ and effectiveness $(\boldsymbol{\eta})$ of backpulses (test 2 ) and backwashings (test 3 and test 4) as flux maintenance strategies.

\begin{tabular}{ccccc}
\hline & Test 1 & Test 2 & Test 3 & Test 4 \\
\hline$\Delta T M P_{\text {test }}$ & 0.53 & 0.48 & 0.43 & 0.28 \\
$\boldsymbol{\eta}$ & $0 \%$ & $9 \%$ & $19 \%$ & $47 \%$ \\
\hline
\end{tabular}

After test 4, in order to improve the permeate production, a new test was performed increasing $50 \%$ of the controlled permeate flux $\left(100 \mathrm{~L} \cdot \mathrm{m}^{-2} \cdot \mathrm{h}^{-1}\right)$. However, under these conditions, a flux decrease of $55 \%$ was observed in the 24 hour assay which indicated that, for the oily wastewater tested, it was not possible to maintain this higher flux even when the flux maintenance systems are applied.

Using the optimal conditions (test 4), that allowed operation at a lower transmembrane pressure variation, a fouling rate was calculated using the TMP values recorded between 10 and $24 \mathrm{~h}$. The fouling rate obtained $\left(6 \times 10^{-4} \mathrm{bar} / \mathrm{h}\right)$ was used to estimate the time needed to achieve 0.64 bar (the TMP obtained without flux maintenance strategies). The result obtained estimates an operation of 19 days using the optimal conditions proposed and shows that a long term continuous operation (without the need to stop the process and perform chemical cleanings) can be expected using these conditions.

Table 5 summarizes the percent rejection and adsorption/deposition related with the different parameters - total solids, total suspended solids, chemical oxygen demand, total organic carbon and 
oil and grease. The apparent rejection of the different parameters was calculated according to the following equation:

$$
\% \text { Apparent rejection }=\frac{C_{f}-C_{p}}{C_{f}} \times 100
$$

where $C_{f}$ is the concentration of the different parameters in the feed water, $C_{p}$ is the concentration of the different parameters in the permeate stream (Table 6). The percent adsorption or deposition of the different parameters in the total recirculation tests was calculated according to Equation (3).

$$
\% \text { Adsorption } / \text { Deposition }=\frac{C_{f 0} \times V_{f 0}-C_{f 24} \times V_{f 24}}{C_{f 0} \times V_{f 0}} \times 100
$$

where $C_{f 0}$ and $C_{f 24}$ are the concentrations of the parameters in the feed tank at $\mathrm{t}=0$ and 24, respectively and $V_{f 0}$ and $V_{f 24}$ are the volumes of feed at $\mathrm{t}=0$ and $24 \mathrm{~h}$, respectively.

Table 5. Percent total rejection and adsorption/deposition of total solids, total suspended solids,

\begin{tabular}{|c|c|c|c|c|c|c|c|c|}
\hline \multirow{2}{*}{ Parameter } & \multicolumn{2}{|c|}{ Test 1} & \multicolumn{2}{|c|}{ Test 2} & \multicolumn{2}{|c|}{ Test 3} & \multicolumn{2}{|c|}{ Test 4} \\
\hline & $\stackrel{\%}{\%}$ Rejection & $\begin{array}{c}\% \\
\text { Ads/Dep }\end{array}$ & $\begin{array}{c}\% \\
\text { Rejection }\end{array}$ & $\begin{array}{c}\% \\
\text { Ads/Dep }\end{array}$ & $\stackrel{\%}{\%}$ Rejection & $\begin{array}{c}\% \\
\text { Ads/Dep }\end{array}$ & $\begin{array}{c}\% \\
\text { Rejection }\end{array}$ & $\begin{array}{c}\% \\
\text { Ads/Dep }\end{array}$ \\
\hline $\begin{array}{c}\text { Total solids } \\
\text { Total }\end{array}$ & 37 & 12 & 29 & 2 & 49 & 0 & 56 & 12 \\
\hline $\begin{array}{l}\text { suspended } \\
\text { solids }\end{array}$ & $>99.9$ & 49 & $>99.9$ & 24 & 99 & 19 & $>99.9$ & 22 \\
\hline COD & 57 & 30 & 37 & 0 & 64 & 1 & 69 & 3 \\
\hline TOC & 49 & 26 & 60 & 23 & 68 & 0 & 64 & 0 \\
\hline Oil and grease & 97 & 89 & 97 & 76 & 99 & 74 & 99 & 46 \\
\hline
\end{tabular}
chemical oxygen demand (COD), total organic carbon (TOC) and oil and grease.

Extremely high percent removals of total suspended solids (>99\%) and oil and grease (>97\%) were observed in tests 1-4. Table 6 shows that membrane filtration ensures removals of these parameters until values lower than the legislation discharge limits. Removal of oil and grease is significantly due to adsorption/deposition on the membrane surface. The high adsorption/deposition of oil and grease was minimized by $48 \%$ using the optimized flux maintenance strategy (test 4 ).

Yang et al. [35] prepared a $\mathrm{ZrO}_{2} / \alpha-\mathrm{Al}_{2} \mathrm{O}_{3}$ microfiltration membrane to treat oil-in-water emulsions, obtaining removals higher than $99 \%$ of oil. However, the hydraulic permeability of the microfiltration membranes were much lower than the hydraulic permeability of the silicon carbide membranes used in this work. Cui et al. [23] also reported removals higher than $99 \%$ of oil when using $\mathrm{NaA} / \alpha-\mathrm{Al}_{2} \mathrm{O}_{3}$ membranes to treat oil-in-water emulsions. In this case, the permeate fluxes were only 5 and $18 \mathrm{~L} \cdot \mathrm{m}^{-2} \cdot \mathrm{h}^{-1}$, with a filtration time of $600 \mathrm{~min}$. Regarding polymeric membranes, good oil and grease removals were also reported but with higher transmembrane pressures [36,37]. Ochando-Pulido et al. [38] achieved extremely high removals of total suspended solids from olive mill wastewaters by an ultrafiltration process using polymeric membranes but, once again, with fluxes not higher than $10 \mathrm{~L} \cdot \mathrm{m}^{-2} \cdot \mathrm{h}^{-1}$. The silicon carbide membranes tested in this study ensure extremely high removals of oil and grease and total suspended solids allowing high permeate fluxes with low transmembrane pressure.

Lower removals of total solids, chemical oxygen demand and total organic carbon were observed, achieving up to $69 \%$ of chemical oxygen demand rejection in test 4 and $68 \%$ of total organic carbon rejection in test 3 . Using the optimized conditions, higher values of rejection of all the tested parameters, except TOC, were obtained by ultrafiltration (this study, Table 5, test 4) compared to the removal values obtained by dissolved air flotation reported in a previous study (Total solids: $27 \%$, total suspended solids: 98\%, COD: 67\%, TOC: 72\%, Oil and grease: 77\%; [39]). Ultrafiltration can therefore be applied instead of flotation for the treatment of olive mill wastewaters. COD removal was not enough to achieve values under the limit legislated. However, good percent removals were achieved when 
compared with other studied membrane processes: Coskun et al. [40] achieved the same range of removals combining ultrafiltration and nanofiltration to treat olive mill wastewaters. A previous study [41] obtained a maximum removal of 15\% of COD from an olive mill wastewater using a regenerated cellulose membrane in dead-end configuration. The results obtained in this study are extremely promising since tests were performed using robust ceramic membranes and in conditions closer to reality in terms of flow dynamics. The membranes tested can achieve good removals with only one membrane step, maintaining a high permeate flux, during prolonged operation periods, with a low transmembrane pressure increase.

Higher percent adsorption/deposition values were reported in the assay without flux maintenance strategies (test 1 ) compared to the assays conducted with backpulse (test 2) and the tests conducted with backpulse and backwash (tests 3 and 4). These results were expected since backpulse and backwash are used to release the fouling components from the membrane surface.

Table 6. Characterization of feed and permeate in terms of total solids, total suspended solids (TSS), chemical oxygen demand (COD), total organic carbon (TOC) and oil and grease in tests 1-4.

\begin{tabular}{|c|c|c|c|c|c|c|c|c|c|c|c|c|}
\hline \multirow[b]{2}{*}{$\begin{array}{l}\text { Concentration } \\
(\mathrm{mg} / \mathrm{L})\end{array}$} & \multicolumn{3}{|c|}{ Test 1} & \multicolumn{3}{|c|}{ Test 2} & \multicolumn{3}{|c|}{ Test 3} & \multicolumn{3}{|c|}{ Test 4} \\
\hline & $\begin{array}{c}\text { Feed } \\
0 \mathrm{~h}\end{array}$ & $\begin{array}{c}\text { Feed } \\
24 \mathrm{~h}\end{array}$ & $\begin{array}{c}\text { Permeate } \\
24 \mathrm{~h}\end{array}$ & $\begin{array}{c}\text { Feed } \\
0 \mathrm{~h}\end{array}$ & $\begin{array}{c}\text { Feed } \\
24 \mathrm{~h}\end{array}$ & $\begin{array}{c}\text { Permeate } \\
24 \mathrm{~h}\end{array}$ & $\begin{array}{c}\text { Feed } \\
0 \mathrm{~h}\end{array}$ & $\begin{array}{c}\text { Feed } \\
24 \mathrm{~h}\end{array}$ & $\begin{array}{c}\text { Permeate } \\
24 \mathrm{~h}\end{array}$ & $\begin{array}{c}\text { Feed } \\
0 \mathrm{~h}\end{array}$ & $\begin{array}{c}\text { Feed } \\
24 \mathrm{~h}\end{array}$ & $\begin{array}{c}\text { Permeate } \\
24 \mathrm{~h}\end{array}$ \\
\hline Total solids & 7012 & 5664 & 4416 & 5232 & 4692 & 3728 & 6148 & 6072 & 3108 & 6644 & 5168 & 2944 \\
\hline TSS & 1525 & 770 & 1.7 & 843 & 640 & 1.8 & 2233 & 1813 & 12 & 3432 & 2460 & 5.6 \\
\hline COD & 8824 & 5752 & 3756 & 7085 & 6715 & 4465 & 9708 & 9264 & 3516 & 9264 & 8468 & 2832 \\
\hline TOC & 2247 & 1530 & 1152 & 2812 & 2031 & 1120 & 2813 & 3126 & 904 & 2346 & 2623 & 856 \\
\hline Oil and grease & 270 & 30 & 7.6 & 250 & 58 & 8.5 & 360 & 93 & 4 & 220 & 89 & 3 \\
\hline
\end{tabular}

The total membrane resistance $\left(R_{t}\right)$, corresponding to the sum of the membrane resistance $\left(R_{m}\right)$ and the resistance due to fouling $\left(R_{f}\right)$ in tests 1 to 4 was calculated at $\mathrm{t}=24 \mathrm{~h}$ using Equation (4):

$$
R_{t}=R_{m}+R_{f}=\frac{T M P}{\mu_{t} \times J}
$$

where TMP refers to the transmembrane pressure, $J$ to the permeate flux and $\mu_{\mathrm{t}}$ to the fluid viscosity corrected to the working temperature, according to Equation (5) [42]:

$$
\mu_{t}=1.784-(0.0575 \times T)+\left(0.0011 \times T^{2}\right)-\left(10^{-5} \times T^{3}\right)
$$

The value of the membrane resistance was determined $\left(R_{m}=1.58 \times 10^{11} \mathrm{~m}^{-1}\right)$ using the value of the hydraulic permeability determined during clean water flux measurements. In order to analyse the effect of the cleaning strategies in the fouling formation, the values of resistance due to fouling of tests 1-4 were calculated and results clearly show the effect of backpulse and backwash strategies in the total resistance of the membrane. In test 1 , conducted without flux maintenance strategies, the resistance of the membrane due to fouling at the end of the test was $4.14 \times 10^{12} \mathrm{~m}^{-1}$. The use of backpulses each $10 \mathrm{~min}$ resulted in a decrease of the resistance of the membrane due to fouling to $3.75 \times 10^{12} \mathrm{~m}^{-1}$. With backwashes each two hours in addition to the backpulses $\left(R_{f}=3.54 \times 10^{12} \mathrm{~m}^{-1}\right)$ the difference was minor but when backwashes were performed each hour an accentuated decrease in membrane resistance due to fouling was observed $\left(2.29 \times 10^{12} \mathrm{~m}^{-1)}\right.$. The considerable reduction in the resistance due to fouling, observed in test 4 , may be interpreted taking into consideration the results presented in Table 5. The only parameter that could justify this difference taking into account the deposition/adsorption results is oil and grease. Therefore, it can be concluded that the reduction of the fouling resistance can be due to an effective release of oil and grease from the surface of the membrane when backpulses each $10 \mathrm{~min}$ are combined with backwashes every hour. The conditions employed in test 4 were therefore applied in a final concentration study, that better simulates real filtration conditions, conducted with total recirculation of the retentate and total recovery of the permeate. 


\subsubsection{Optimization of Membrane Cleaning}

In order to optimize the cleaning protocol of the membrane, different cleaning solutions were tested and analysed in terms of total suspended solids and oil and grease- the contaminants considered to be the most important in fouling formation. In all tests, the first cleaning step was a rinsing step with hot water $\left(60 \pm 5^{\circ} \mathrm{C}\right)$. Alkaline and acid solutions were tested after the rinsing step, and the effect of the temperature of the cleaning solutions was studied.

The first approach included the use of a $4 \% \mathrm{NaOH}$ solution, recommended by the membrane manufacturer since it has a low cost, is easily available and can efficiently remove the oil and grease adsorbed on the surface of the membrane [43].

Figure 4a shows the permeability of the membrane recovered after each cleaning step in test 1. Results show that rinsing and using $\mathrm{NaOH}$ at controlled temperature $\left(60 \pm 5^{\circ} \mathrm{C}\right)$ was not enough to recover the permeability of the membrane. A solution of $2 \%$ citric acid was therefore employed. The results obtained show that the permeability was totally restored. It was thus concluded that the use of an acid solution may also be important to recover the permeability of the membrane with this wastewater.

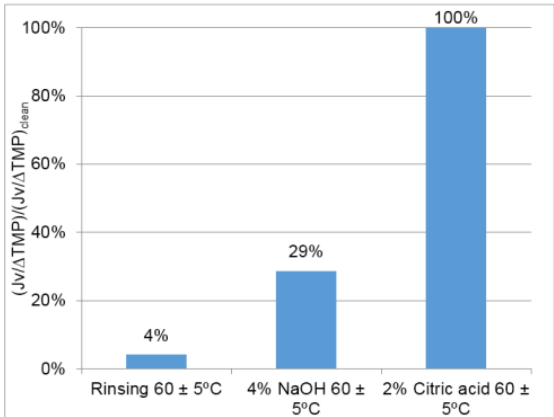

(a)

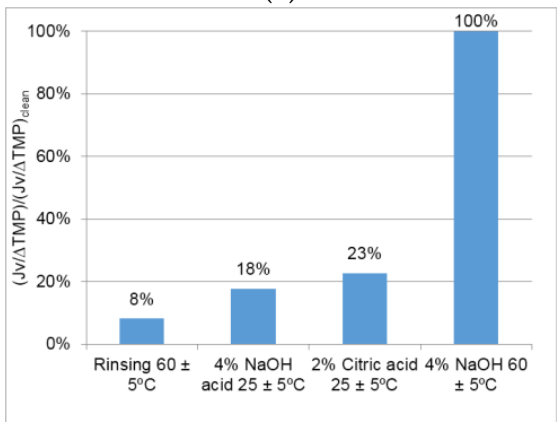

(c)

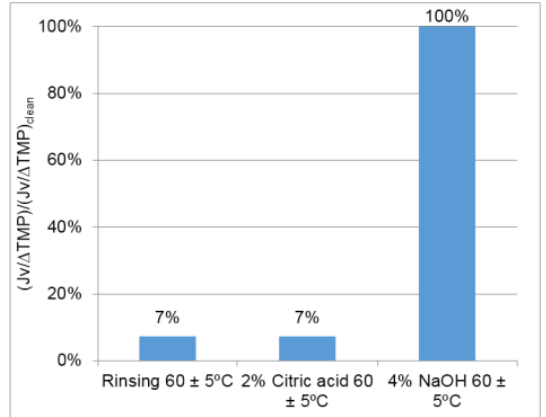

(b)

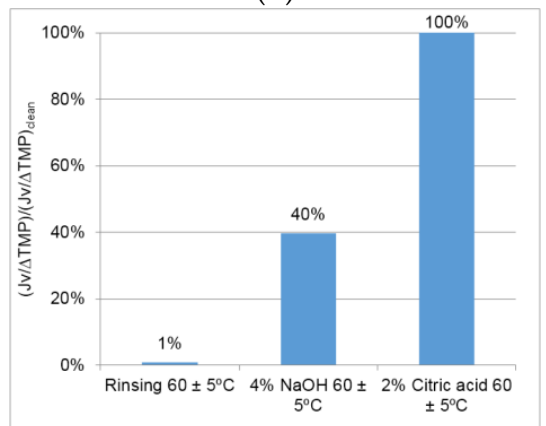

(d)

Figure 4. Percent recovery of the permeate flux per transmembrane pressure applied $\left(J_{v} / \Delta T M P\right) /$ $\left(J_{v} / \triangle T M P\right)_{\text {clean }}$ with different cleaning protocols performed after the membrane filtration assays: (a) test $1 ;$ (b) test $2 ;(\mathbf{c})$ test 3 ; (d) test 4.

After test 2 (Figure $4 b$ ), the strategy to clean the membrane was therefore the use of both acid and alkaline solutions at $60 \pm 5{ }^{\circ} \mathrm{C}$ after an initial rinsing step. In this protocol, the sequence of steps was inverted, with the acid cleaning performed before the alkaline cleaning. The acid solution by itself was not enough to recover the permeability and only $6.5 \%$ of the adsorbed total suspended solids were recovered in this step. Even though total suspended solids and oil and grease were not detected after the acid cleaning step, a quick recovery of permeability was obtained using the consecutive acid and basic cleaning agents.

To understand if the use of a high temperature was really needed, cleaning after test 3 was performed with acid and alkaline solutions at room temperature $-25^{\circ} \mathrm{C}$ after rinsing with hot water 
(Figure 7c). The cleanings performed at $25^{\circ} \mathrm{C}$ were not enough to restore the membrane permeability. After cleaning with $\mathrm{NaOH}$ at $60 \pm 5^{\circ} \mathrm{C}$, the permeability was totally restored, so it was concluded that it is necessary to increase the temperature at least in one step of the chemical cleaning. A total of $100 \%$ of the suspended solids and $23 \%$ of the oil and grease adsorbed on the membrane were detected after analysing the cleaning solutions. Again, rinsing with hot water proved to be the most important step in the removal of total suspended solids (57\%) and oil and grease (100\%); $4 \%$ of the adsorbed total suspended solids was detected in the acid solution.

To study if the sequence of the chemical cleanings was important, in test 4 (Figure $4 \mathrm{~d}$ ) this procedure was performed after rinsing with an alkaline cleaning followed by an acid cleaning both at $60 \pm 5{ }^{\circ} \mathrm{C}$. It was observed that the permeability was totally restored after a sequence of basic and acid cleaning steps, indicating that the sequence does not seem to be important (compared with Figure $7 \mathrm{~b}$ ). Nevertheless, alternating alkaline and acid cleanings seems to be important in addition to the temperature: results indicate that the first chemical cleaning contributes to the destructuring of the existent fouling facilitating the subsequent cleaning. Furthermore, $75 \%$ of the total suspended solids removed using this cleaning protocol were recovered in the rinsing step, $21 \%$ in the alkaline cleaning and $4 \%$ in the acid cleaning. In sum, $82 \%$ of the total suspended solids adsorbed on the membrane surface were recovered in the cleaning procedure. All the adsorbed oil and grease were recovered in the rinsing step. Since the permeate flux was totally restored after the proposed cleaning procedure, the results indicate that total suspended solids, oil and grease and inorganic matter are important agents involved in fouling formation during the filtration of these wastewaters.

\subsubsection{Concentration Test}

Figure 5 shows the TMP variation during the concentration test. During the first hour, the flux was set at $67 \mathrm{~L} \cdot \mathrm{m}^{-2} \cdot \mathrm{h}^{-1}$ and backpulses every $10 \mathrm{~min}$ were performed in addition to backwashes every hour; the optimized conditions were determined in the total recirculation tests. The transmembrane pressure variation during the first hour was only 0.02 bar, very low compared to 0.15 bar variation obtained in the same period in the total recirculation assay-Figure $3 \mathrm{~d}$. In order to increase the process efficiency, the controlled permeate flux was therefore increased $50 \%$ in relation to the initial permeate flux, to $100 \mathrm{~L} \cdot \mathrm{m}^{-2} \cdot \mathrm{h}^{-1}$, while keeping the flux maintenance strategies previously optimized.

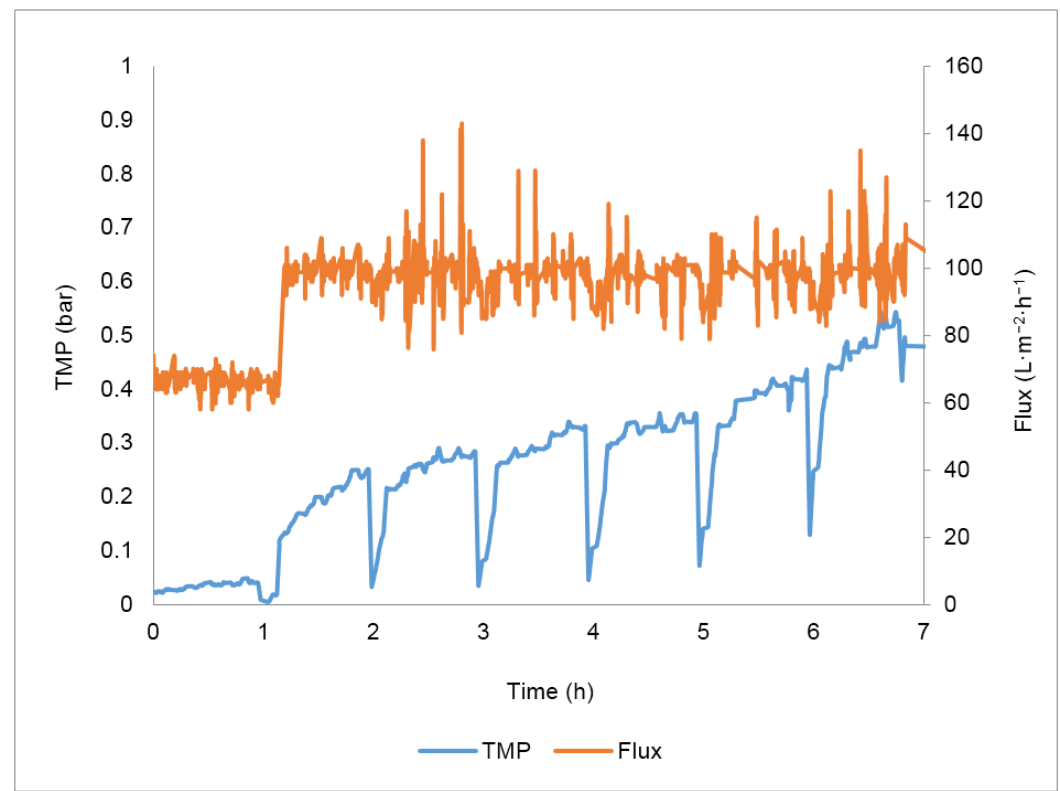

Figure 5. Transmembrane pressure (TMP) and permeate flux profiles obtained in the concentration test. 
The lower transmembrane pressure variation in this assay was due to a better quality of the large volume of oily wastewater received for the concentration study (Table 7), that was much less concentrated in terms of the water quality parameters analysed.

$$
\text { Concentration factor }=\frac{\text { Volume feed }}{\text { Volume feed }- \text { Volume permeate }}
$$

Table 7. Characterization of the olive mill wastewater used in the concentration test in terms of total solids, total suspended solids, chemical oxygen demand (COD), total organic carbon (TOC) and oil and grease.

\begin{tabular}{cc}
\hline Parameter & Concentration $(\mathbf{m g} / \mathrm{L})$ \\
\hline Total solids & 1946 \\
Total suspended solids & 438 \\
COD & 1850 \\
TOC & 305 \\
\hline
\end{tabular}

In these conditions, a final concentration factor (Equation (6)) of 5.2 was achieved, corresponding to a permeate recovery of $81 \%$.

Figure 6 presents the percent rejection of the different parameters obtained in samples collected during the concentration assay.

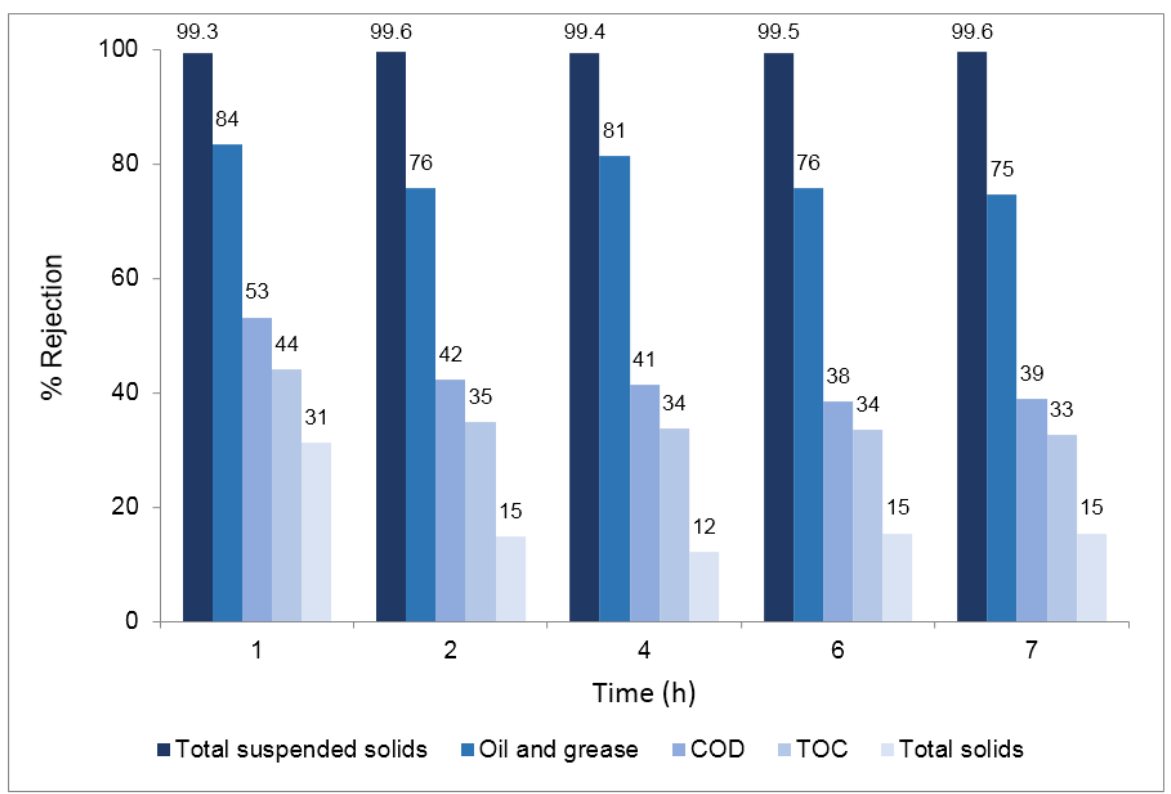

Figure 6. Percent rejection of total suspended solids, oil and grease, chemical oxygen demand (COD), total organic carbon (TOC) and total solids-Concentration test.

Results show that the rejections of the different parameters monitored were maintained during the $7 \mathrm{~h}$ concentration study, evidencing that the quality of the permeate over time was not deteriorated despite the increasing concentration of the different components in the feed wastewater due to the total recirculation of the retentate. The results obtained in terms of rejection were consistent with the results previously obtained in the $24 \mathrm{~h}$ total recirculation test. The silicon carbide membranes used ensure high removals of total suspended solids and oil and grease. The value of membrane resistance at working temperature due to fouling at the end of this test was $2.31 \times 10^{12} \mathrm{~m}^{-1}$. 
Huang et al. [44] adapted the Hermia's model [45] to describe fouling mechanisms in membrane processes performed at constant TMP and developed a similar one for membrane processes conducted at controlled permeate flux. This model was applied to the results obtained in the concentration test in order to identify the different fouling mechanisms involved. The results obtained indicate that the main fouling mechanism involved in this process is cake formation, since it presents the best coefficient of determination (0.92). This result is in accordance with other published studies, where the fouling formation during the ultrafiltration of oily wastewaters is mainly attributed to cake formation [46,47]. This fouling mechanism is attributed to the deposit of large molecules on the membrane surface. Results are thus in accordance with the assumption that total suspended solids and oil and grease are important parameters in fouling formation [48].

Figure 7 relates the maximum TMP achieved before backwashes with the concentration of total suspended solids present in the feed at the same time. A linear regression with a coefficient of determination $\left(\mathrm{R}^{2}\right)$ of 0.99 was obtained, indicating a strong relationship between these two variables and confirming the influence of the concentration of total suspended solids present in the feed in the cake formation.

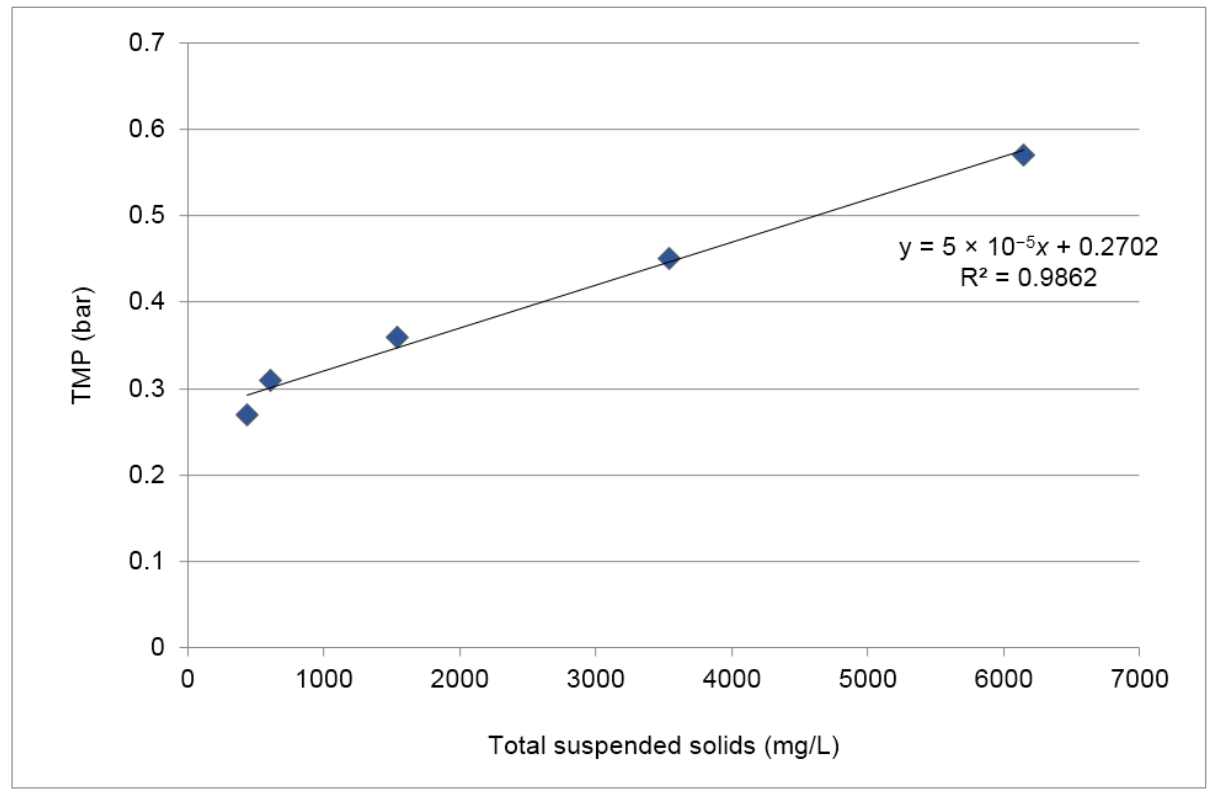

Figure 7. Impact of total suspended solids present in the feed in TMP-Concentration test.

The optimized cleaning procedure was applied after the concentration test to restore the membrane permeability. In this case, after the alkaline step, the permeability was totally restored and the acid cleaning step was therefore not needed. This may be due to the better quality of the wastewater. All the adsorbed total suspended solids and oil and grease were recovered.

\section{Conclusions}

This work shows that a new generation of silicon carbide membranes can be used to ensure extremely high removals of total suspended solids and oil and grease and moderate removals of chemical oxygen demand (COD) and total organic carbon (TOC) from olive mill wastewaters. Removal of oil and grease was largely due to adsorption/deposition of the compounds on the surface of the membrane and harder to remove using the flux maintenance strategies compared with other fouling agents.

The employment of backpulses every $10 \mathrm{~min}$ is an effective strategy to achieve a reduction of the fouling formation at the surface of the membrane since it enables a release of the adsorbed compounds. When the backpulses are combined with backwashes, the percent of adsorption/deposition of the 
analysed compounds is further reduced. The combination of backpulses every $10 \mathrm{~min}$ and backwash every $1 \mathrm{~h}$ helps minimize fouling, maintain flux and avoid high TMP increase. A high reduction of adsorption/deposition of oil and grease in the membrane surface was observed. This result can explain the decrease of the resistance due to the fouling observed when working under the determined optimum constant permeate flux $\left(67 \mathrm{~L} \cdot \mathrm{m}^{-2} \cdot \mathrm{h}^{-1}\right)$ together with backpulses every $10 \mathrm{~min}$ and backwashes every hour, indicating that oil and grease is an important component of fouling.

To recover the membrane permeability, the simplest and most effective strategy is to rinse and alternate a basic and an acid cleaning solution. All these steps must be performed at controlled temperature, between 60 and $65^{\circ} \mathrm{C}$. Rinsing at $60-65^{\circ} \mathrm{C}$ seems to be the step that most contributes to the removal of oil and grease and total suspended solids, followed by the basic cleaning with $4 \% \mathrm{NaOH}$.

Results demonstrate that membrane filtration using this new generation of silicon carbide membranes is extremely effective to remove total suspended solids and oil and grease from different real olive mill effluents and thus constitute a promising alternative to conventional wastewater treatment processes.

This process allowed us to obtain water with concentrations of total suspended solids and oil and grease below the maximum levels legislated for direct discharge in the environment. However, high contents of dissolved organic components are still present and must be further removed. Processes such as nanofiltration [39] or advanced oxidation processes [2,7,49] may be good options to reduce it and to guarantee the production of high quality water.

Acknowledgments: The authors thank Adventech for supplying the wastewater matrices and Liqtech for supplying the silicon carbide membranes used in this study, in the frame of EC project O-WaR. Financial support from the EU FP7/SME theme [SME-2013-1] through the project O-WaR (grant agreement no: 605641) as well as from FCT through the post-doc fellowship SFRH/BPD/94303/2013 are gratefully acknowledged. iNOVA4Health-UID/Multi/04462/2013, a program financially supported by Fundação para a Ciência e Tecnologia/Ministério da Educação e Ciência, through national funds and co-funded by FEDER under the PT2020 Partnership Agreement, is also gratefully acknowledged. This work was also supported by the Associate Laboratory for Green Chemistry LAQV which is financed by national funds from FCT/MEC (UID/QUI/50006/2013) and co-financed by the ERDF under the PT2020 Partnership Agreement (POCI-01-0145-FEDER-007265).

Author Contributions: All the authors designed the experiments and analysed the data. Maria do Carmo Fraga performed the experiments and wrote the paper; Sandra Sanches was involved in the development and validation of the analytical methods; Vanessa Pereira and João Crespo supervised the experimental work and the elaboration of the manuscript.

Conflicts of Interest: The authors declare no conflict of interest.

\section{References}

1. Cheryan, M.; Rajagopalan, N. Membrane processing of oily streams. Wastewater treatment and waste reduction. J. Membr. Sci. 1998, 151, 13-28. [CrossRef]

2. Brenes, M.; García, A.; García, P.; Rios, J.J.; Garrido, A. Phenolic Compounds in Spanish Olive Oils. J. Agric. Food Chem. 1999, 47, 3535-3540. [CrossRef] [PubMed]

3. Kapellakis, I.E.; Tsagarakis, K.P.; Avramaki, C.; Angelakis, A.N. Olive mill wastewater management in river basins: A case study in Greece. Agric. Water Manag. 2006, 82, 354-370. [CrossRef]

4. Cicci, A.; Stoller, M.; Bravi, M. Microalgal biomass production by using ultra- and nanofiltration membrane fractions of olive mill wastewater. Water Res. 2013, 47, 4710-4718. [CrossRef] [PubMed]

5. Mseddi, S.; Chaari, L.; Belaid, C.; Chakchouk, I.; Kallel, M. Valorization of treated olive mill wastewater in fertigation practice. Environ. Sci. Pollut. Res. 2016, 23, 15792-15800. [CrossRef] [PubMed]

6. Rusan, M.J.M.; Abalasmed, A.A.; Zuraiqi, S.; Bashabsheh, M. Evaluation of phytotoxicity effect of olive mill wastewater treated by different technologies on seed germination of barley (Hordeum vulgare L.). Environ. Sci Pollut Res. 2015, 22, 9127-9135. [CrossRef] [PubMed]

7. Justino, C.; Marques, A.G.; Duarte, K.R.; Duarte, A.C.; Pereira, R.; Rocha-Santos, T.; Freitas, A.C. Degradation of phenols in olive oil mill wastewater by biological, enzymatic, and photo-Fenton oxidation. Environ. Sci Pollut Res. 2010, 17, 650-656. [CrossRef] [PubMed] 
8. Ochando-Pulido, J.M.; Hodaifa, G.; Victor-Ortega, M.D.; Martinez-Ferez, A. Performance modeling and cost analysis of a pilot-scale reverse osmosis process for the final purification of olive mill wastewater. Membranes 2013, 3, 285-297. [CrossRef] [PubMed]

9. Cassano, A.; Conidi, C.; Giorno, L.; Drioli, E. Fractionation of olive mill wastewaters by membrane separation techniques. J. Hazard Mater. 2013, 248-249, 185-193. [CrossRef] [PubMed]

10. Ochando-Pulido, J.M.; Martinez-Ferez, A. On the recent use of membrane technology for olive mill wastewater purification. Membranes 2015, 5, 513-531. [CrossRef] [PubMed]

11. Han, G.; Wit, J.S.; Chung, T.S. Water reclamation from emulsified oily wastewater via effective forward osmosis hollow fiber membranes under the PRO mode. Water Res. 2015, 81, 54-63. [CrossRef] [PubMed]

12. Padaki, M.; Surya Murali, R.; Abdullah, M.S.; Misdan, N.; Moslehyani, A.; Kassim, M.A.; Hilal, N.; Ismail, A.F. Membrane technology enhancement in oil-water separation. A review. Desalination 2015, 357, 197-207. [CrossRef]

13. Um, M.J.; Yoon, S.H.; Lee, C.H.; Chung, K.Y.; Kim, J.J. Flux enhancement with gas injection in crossflow ultrafiltration of oily wastewater. Water Res. 2001, 35, 4095-4101. [CrossRef]

14. Van der Bruggen, B.; Vandecasteele, C.; Van Gestel, T.; Wim, D.; Leysen, R. A review of pressure-driven membrane processes in wastewater treatment and drinking water production. Environ. Prog. Sustain. Energy 2003, 22, 46-56. [CrossRef]

15. Mondal, S.; Wickramasinghe, S.R. Produced water treatment by nanofiltration and reverse osmosis membranes. J. Membrane Sci. 2008, 322, 162-170. [CrossRef]

16. Baker, R.W. Membrane Technology and Applications; John Wiley \& Sons, Ltd.: Chichester, UK, 2004.

17. Miller, D.J.; Paul, D.R.; Freeman, B.D. A crossflow filtration system for constant permeate flux membrane fouling characterization. Rev. Sci. Instrum. 2013, 84. [CrossRef] [PubMed]

18. Field, R.W.; Wu, D.; Howell, J.A.; Gupta, B.B. Critical flux concept for microfiltration fouling. J. Membr. Sci. 1995, 100, 259-272. [CrossRef]

19. Miller, D.J.; Kasemset, S.; Paul, D.R.; Freeman, B.D. Comparison of membrane fouling at constant flux and constant transmembrane pressure conditions. J. Membr. Sci. 2014, 454, 505-515. [CrossRef]

20. Bacchin, P.; Aimar, P.; Field, R.W. Critical and sustainable fluxes: Theory, experiments and applications. J. Membr. Sci. 2006, 281, 42-69. [CrossRef]

21. Field, R.W.; Pearce, G.K. Critical, sustainable and threshold fluxes for membrane filtration with water industry applications. Adv. Colloid Interface Sci. 2011, 164, 38-44. [CrossRef] [PubMed]

22. Abadi, S.R.H.; Sebzari, M.R.; Hemati, M.; Rekabdar, F.; Mohammadi, T. Ceramic membrane performance in microfiltration of oily wastewater. Desalination 2011, 265, 222-228. [CrossRef]

23. Cui, J.; Zhang, X.; Liu, H.; Liu, S.; Yeung, K.L. Preparation and application of zeolite/ceramic microfiltration membranes for treatment of oil contaminated water. J. Membr. Sci. 2008, 325, 420-426. [CrossRef]

24. Weschenfelder, S.E.; Borges, C.P.; Campos, J.C. Oilfield produced water treatment by ceramic membranes: Bench and pilot scale evaluation. J. Membr. Sci. 2015, 495, 242-251. [CrossRef]

25. Ramirez, J.A.; Davis, R.H. Application of cross-flow microfiltration with rapid backpulsing to wastewater treatment. J. Hazard. Mater. 1998, 63, 179-197. [CrossRef]

26. Luque, S.; Gómez, D.; Álvarez, J.R. Industrial Applications of Porous Ceramic Membranes (Pressure-Driven Processes). Membr. Sci. Technol. 2008, 13, 177-216.

27. Kumar, R.V.; Ghoshal, A.K.; Pugazhenthi, G. Elaboration of novel tubular ceramic membrane from inexpensive raw materials by extrusion method and its performance in microfiltration of synthetic oily wastewater treatment. J. Membr. Sci. 2015, 490, 92-102. [CrossRef]

28. Moulin, C.; Bourbigot, M.M.; Tazi-Pain, A.; Bourdon, F. Design and performance of membrane filtration installations: Capacity and product quality for drinking water applications. Environm. Technol. 1991, 12, 841-858. [CrossRef]

29. Zhong, J.; Sun, X.; Wang, C. Treatment of oily wastewater produced from refinery processes using flocculation and ceramic membrane filtration. Sep. Purif. Technol. 2003, 32, 93-98. [CrossRef]

30. Deng, W.; Yu, X.; Sahimi, M.; Tsotsis, T.T. Highly permeable porous silicon carbide support tubes for the preparation of nanoporous inorganic membranes. J. Membr. Sci. 2014, 451, 192-204. [CrossRef]

31. König, K.; Boffa, V.; Buchbjerg, B.; Farsi, A.; Christensen, M.L.; Magnacca, G.; Yue, Y. One-step deposition of ultrafiltration $\mathrm{SiC}$ membranes on macroporous SiC supports. J. Membr. Sci. 2014, 472, 232-240. [CrossRef] 
32. Hofs, B.; Ogier, J.; Vries, D.; Beerendonk, E.F.; Cornelissen, E.R. Comparison of ceramic and polymeric membrane permeability and fouling using surface water. Sep. Purif. Technol. 2011, 79, 365-374. [CrossRef]

33. Fraga, M.C.; Sanches, S.; Pereira, V.J.; Crespo, J.G.; Yuan, L.; Marcher, J.; Martínez de Yuso, M.V.; Rodríguez-Castellón, E.; Benavente, J. Morphological, chemical surface and filtration characterization of a new silicon carbide membrane. J. Eur. Ceram. Soc. 2017, 37, 899-905. [CrossRef]

34. Eaton, A.D.; Clesceri, L.S.; Greenberg, A.E. Standard Methods for the Examination of Water and Wastewater, 19th ed.; American Public Health Association: Washington, DC, USA, 2005.

35. Yang, C.; Zhang, G.; Xu, N.; Shi, J. Preparation and application in oil-water separation of $\mathrm{ZrO}_{2} / \alpha-\mathrm{Al}_{2} \mathrm{O}_{3} \mathrm{MF}$ membrane. J. Membrane Sci. 1998, 142, 235-243. [CrossRef]

36. Muppalla, R.; Jewrajka, S.K.; Reddy, A.V.R. Fouling resistant nanofiltration membranes for the separation of oil-water emulsion and micropollutants from water. Sep. Pur. Technol. 2015, 143, 125-134. [CrossRef]

37. Rajasekhar, T.; Trinadh, M.; Veera Babu, P.; Sainath, A.V.S.; Reddy, A.V.R. Oil-water emulsion separation using ultrafiltration membranes based on novel blends of poly(vinylidene fluoride) and amphiphilic tri-block copolymer containing carboxylic acid functional group. J. Membr. Sci. 2015, 481, 82-93. [CrossRef]

38. Ochando-Pulido, J.M.; Stoller, M.; Di Palma, L.; Martínez-Ferez, A. On the optimization of a flocculation process as fouling inhibiting pretreatment on an ultrafiltration membrane during olive mill effluents treatment. Desalination 2016, 393, 151-158. [CrossRef]

39. Sanches, S.; Fraga, M.C.; Siilva, N.A.; Nunes, P.; Crespo, J.G.; Pereira, V.J. Pilot scale nanofiltration treatment of olive mill wastewater: A technical and economical evaluation. Environ. Sci. Pollut. Res. 2016, in press. [CrossRef] [PubMed]

40. Coskun, T.; Debik, E.; Demir, N.M. Treatment of olive mill wastewaters by nanofiltration and reverse osmosis membranes. Desalination 2010, 259, 65-70. [CrossRef]

41. Martins, R.C.; Ferreira, A.M.; Gando-Ferreira, L.M.; Quinta-Ferreira, R.M. Ozonation and ultrafiltration of olive mill wastewaters: effect of key operating conditions and integration schemes. Environ. Sci. Pollut. Res. 2015, 22, 15587-15597. [CrossRef] [PubMed]

42. US EPA. Membrane filtration guidance manual; EPA 815-R-06-009; Office of Water (4601): Cincinnati, OH, USA, 2005; p. 332.

43. LiqTech. Flux Maintenance on Ceramic Silicon Carbide Membranes; LiqTech international A/S: Ballerup, Denmark, 2014.

44. Huang, H.; Young, T.A.; Jacangelo, J.G. Unified membrane fouling index for low pressure membrane filtration of natural waters: Principles and methodology. Environ. Sci. Technol. 2008, 42, 714-720. [CrossRef] [PubMed]

45. Hermia, J. Constant pressure blocking filtration laws-Application to power-law non-Newtonian fluids. Inst. Chem. Eng. Trans. 1982, 60, 183-187.

46. Salahi, A.; Abbasi, M.; Mohammadi, T. Permeate flux decline during UF of oily wastewater: Experimental and modeling. Desalination 2010, 251, 153-160. [CrossRef]

47. Zhou, J.; Wanderac, D.; Husson, S.M. Mechanisms and control of fouling during ultrafiltration of high strength wastewater without pretreatment. J. Membr. Sci. 2015, 488, 103-110. [CrossRef]

48. Vasanth, D.; Pugazhenthi, G.; Uppaluri, R. Fabrication and properties of low cost ceramic microfiltration membranes for separation of oil and bacteria from its solution. J. Membr. Sci. 2011, 379, 154-163. [CrossRef]

49. Amaral-Silva, N.; Martins, R.C.; Castro-Silva, S.; Quinta-Ferreira, R.M. Integration of traditional systems anss advanced oxidation process technologies for the industrial treatment of olive mill wastewaters. Environ. Technol. 2016, 37, 2524-2535. [CrossRef] [PubMed]

(C) 2017 by the authors. Licensee MDPI, Basel, Switzerland. This article is an open access article distributed under the terms and conditions of the Creative Commons Attribution (CC BY) license (http:/ / creativecommons.org/licenses/by/4.0/). 